\title{
FAKTOR RISIKO STUNTING PADA BALITA
}

\author{
Winarni Hamzah ${ }^{1}$, Haniarti $^{2}$, Rini Anggraeny ${ }^{3}$ \\ ${ }^{1}$ Mahasiswa Konsentrasi Epidemiologi Fakultas Ilmu Kesehatan, Universitas \\ Muhammadiyah Parepare \\ 2,3 Dosen Program Studi Kesehatan Masyarakat, Universitas Muhammadiyah \\ Parepare
}

Email: winarnihamzah@yahoo.com

\begin{abstract}
ABSTRAK
Stunting merupakan salah satu masalah gizi yang dialami oleh balita di dunia saat ini. Pada tahun 2017 sebanyak 22,2\% balita di dunia mengalami Stunting. Indonesia termasuk ke dalam negara ketiga dengan prevalensi tertinggi di regional asia tenggara, prevalensi balita Stunting di Indonesia tahun 2005-2017 adalah 36,4\%. Bertujuan untuk mengetahui faktor risiko Stunting pada balita di wilayah kerja Puskesmas Baraka Kabupaten Enrekang. Penelitian ini menggunakan metode Survey analitik dengan pendekatan Cross SectionalStudy menggunakan teknik pengambilan sampel Simple Random Samplingyang artinya sampel yang diambil merupakan dimana setiap elemen atau anggota populasi memiliki kesempatan yang sama untuk terpilih menjadi sampel. Besar sampel dalam penelitian ini diambil dengan menggunakan rumus SlovinLokasi dilakukan di wilayah kerja Puskesmas Baraka Kabupaten Enrekang. Adapun waktu penelitian selama 1 bulan. Sampel dalam penelitian ini berjumlah 94 orang dengan proses pengambilan data dan pengumpulan data dilakukan dengan teknik wawancara. Hasil penelitian menunjukkan bahwa ASI Eksklusif $(\mathrm{p}=0,002)$, MP ASI $(\mathrm{p}=0,002)$ mempunyai hubungan terhadap kejadian Stunting, sedangkan tidak ada hubungan antara BBLR $(\mathrm{p}=0,106)$, usia kehamilan $(\mathrm{p}=0,303)$, dan status gizi ibu(KEK) $(\mathrm{p}=0,229)$ dengan kejadian Stunting.
\end{abstract}

Kata kunci : ASI eksklusif, BBLR, KEK, MP ASI, Usia kehamilan 


\title{
STUNTING RISK FACTORS IN CHILDREN
}

\begin{abstract}
Stunting is one of the nutritional problems experienced by toddlers in the world today. In 2017, 22.2\% of children under five in the world were stunted. Indonesia is included in the third country with the highest prevalence in the Southeast Asia region, the prevalence of children under five with stunting in Indonesia in 2005-2017 was 36.4\%. Aims to determine the risk factors for stunting in children under five in the working area of the Baraka Community Health Center, Enrekang Regency. This study used the analytical survey method with the Cross Sectional Study approach using the simple random sampling technique, which means that the sample taken is where each element or member of the population has the same opportunity to be selected as the sample. The sample size in this study was taken using the Slovin formula. The location was carried out in the working area of the Baraka Community Health Center, Enrekang Regency. The research time was 1 month. The sample in this study amounted to 94 people with the process of data collection and data collection was carried out by interview techniques. The results showed that exclusive breastfeeding $(p=0.002)$, complementary breastfeeding $(p=0.002)$ had a relationship with the incidence of stunting, while there was no relationship between $L B W(p=0.106)$, gestational age $(p=0.303)$, and maternal nutritional status $(K E K)(p=0.229)$ with the incidence of stunting.
\end{abstract}

Keywords: Exclusive breastfeeding, BBLR, KEK, Breastfeeding, Gestational age

\section{PENDAHULUAN}

Stunting merupakan salah satu masalah gizi yang dialami oleh balita di dunia saat ini. Pada tahun 2017 sebanyak $22,2 \%$ atau sekitar 150,8 juta balita di dunia mengalami Stunting. Data prevalensi balita Stunting yang dikumpulkan World Health Organization (WHO) menunjukkan bahwa Indonesia termasuk ke dalam negara ketiga dengan prevalensi tertinggi di Regional Asia Tenggara/South-East Asia Regional (SEAR). Rata-rata prevalensi balita Stunting di Indonesia tahun 2005-2017 adalah 36,4\% ( Kementrian Kesehatan RI, 2018).

Stunting adalah salah satu masalah gizi yang berdampak buruk terhadapkualitas hidup anak dalam mencapai titik tumbuh kembang yang optimal sesuai potensi genetiknya. Stunting dapat menghambat proses tumbuh kembang pada balita. Chilhood Stunting atau tubuh pendek pada masa anak-anak merupakan akibat kekurangan gizi kronis atau kegagalan pertumbuhan di masa lalu dan digunakan sebagai indikator jangka panjang untuk gizi 
kurang pada anak (Yusdarif, et all., 2018).

Berdasarkan hasil Pemantauan Status Gizi Dinas Kesehatan Kabupaten Enrekang, prevalensi Stunting pada tahun 2017 sebanyak 4.333 balita atau $24,4 \%$. Terjadi penurunan pada tahun 2018 menjadi 3.976 balita atau 23,7\% . Kemudian pada tahun 2019 angka Stunting di Kabupaten Enrekang mengalami peningkatan yaitu 4.004 balita. Akan tetapi prevalensi Stuntingdi Kabupaten Enrekang khususnya di Kecamatan Baraka yang merupakan angka Stunting tertinggi yang mencapai 638 balita. Tujuan dalam penelitian ini adalahbertujuan untuk menganalisis hubungan variabel bebas, faktor-faktor resiko yang berhubungan dengan Stunting yaitu pemberian ASI Eksklusif, Pemberian MP ASI, BBLR, Usia kehamilan dan Riwayat status ibu (KEK) dengan variabel terikat yaitu Stunting pada balita (Dinkes Kabupaten Enrekang, 2019).

\section{METODE PENELITIAN}

Jenis penelitian ini adalah penelitian Survey analitik dengan pendekatan Cross Sectional Study yang menjelaskan hubungan variabel-variabel yang ingin diteliti. Penelitian ini dilakukan dengan cara memberikan lembar kuesioner, pengukur tinggi badan, buku KMS, timbangan dan dilaksanakan di wilayah kerja puskesmas Baraka kabupaten Enrekang. Adapun waktu pelaksanaannya pada bulan Maret sampai April 2020. Populasi pada penelitian ini adalah berjumlah 1484 orang, dengan menggunakan Teknik pengambilan sampel dalam penelitian ini yaitu menggunakan teknik Simple Random Sampling yang artinya sampel yang diambil merupakan dimana setiap elemen atau anggota populasi memiliki kesempatan yang sama untuk terpilih menjadi sampel. Besar sampel dalam penelitian ini diambil dengan menggunakan rumus Slovin yaitu sebanyak 94 sampel. Data yang di peroleh dari puskesmas Baraka, jurnal, serta buku yang berkaitan dengan penelitian saya.

\section{HASIL PENELITIAN}

Penelitian ini telah dilaksanakan di Wilayah Kerja Puskesmas Baraka Kabupaten Enrekang, dengan menggunakan lembar wawancara, pengukur tinggi badan, buku KMS, timbangan, pengumpulan data dilaksanakan pada bulan Maret sampai April 2020, jumlah sampel 94 orang. Penelitian ini dilaksanakan di Wilayah Kerja Puskesmas Baraka Kabupaten Enrekang.

\section{Karakteristik}

respondenberdasarkan pekerjaan (Tabel 1) kategori pekerjaan sebagai PNS yaitu sebanyak 5 orang $(5,3 \%)$, IRT sebanyak 71 orang $(75,5 \%)$, dan Wiraswasta sebanyak 18 orang $(19,1 \%)$. 
Tabel 1. Distribusi Responden Berdasarkan Pekerjaan Terhadap Kejadian Stunting Pada Balita di Wilayah Kerja Puskesmas Baraka Kabupaten Enrekang.

\begin{tabular}{ccc}
\hline Pekerjaan & Frekuensi & Persentase \\
\hline PNS & 5 & 5,3 \\
IRT & 71 & 75,5 \\
Wiraswasta & 18 & 19,1 \\
& & \\
\hline Total & $\mathbf{9 4}$ & $\mathbf{1 0 0 , 0}$
\end{tabular}

\section{Sumber: Data Primer}

Tabel 2 Karakteristik responden berdasarkan ukuran LILA ibu hamil yaitu yang mengalami KEK $(<23,5 \mathrm{~cm})$ sebanyak 33 orang $(35,1 \%)$ dan yang tidak $\operatorname{KEK}(\geq 23,5 \mathrm{~cm})$ sebanyak 61 orang $(64,9 \%)$.

Tabel 2. Distribusi Responden Berdasarkan Ukuran LILA Ibu Hamil Terhadap Kejadian Stunting Pada Balita di Wilayah Kerja Puskesmas Baraka Kabupaten Enrekang.

\begin{tabular}{ccc}
\hline LILA & Frekuensi & Persentase \\
\hline$<23,5 \mathrm{~cm}$ & 33 & 35,1 \\
$\geq 23,5 \mathrm{~cm}$ & 61 & 64,9 \\
\hline Total & $\mathbf{9 4}$ & $\mathbf{1 0 0 , 0}$
\end{tabular}

\section{Sumber: Data Sekunder}

Pada tabel 3 menunjukkan tahun sebanyak 75 orang $(79,8 \%)$ dan distribusi berdasarkan kelompok umur yang berusia 4-5 tahun sebanyak 19 pada balita diamana yang berusia 1-3 orang $(20,2 \%)$.

Tabel 3. Distribusi Berdasarkan Kelompok Umur Pada Balita di Wilayah Kerja Puskesmas Baraka Kabupaten Enrekang.

\begin{tabular}{ccc}
\hline $\begin{array}{c}\text { Karakteristik kelompok } \\
\text { umur(tahun) }\end{array}$ & Frekuensi & Persentase \\
\hline $1-3$ & 75 & 79,8 \\
$4-5$ & 19 & 20,2 \\
\hline Total & $\mathbf{9 4}$ & $\mathbf{1 0 0 , 0}$
\end{tabular}

Sumber: Data Primer 
Tabel 4 menunjukkan distribusi berdasarkan jenis kelamin pada balita yaitu laki laki sebanyak 59 orang
$(62,8 \%)$ dan perempuan sebanyak 35 orang $(37,2 \%)$.

Tabel 4. Distribusi Berdasarkan Jenis Kelamin Pada Balita di Wilayah Kerja Puskesmas Baraka Kabupaten Enrekang.

\begin{tabular}{ccc}
\hline Jenis Kelamin & Frekuensi & Persentase \\
& & \\
\hline Laki-laki & 59 & 62,8 \\
Perempuan & 35 & 37,2 \\
\hline Total & $\mathbf{9 4}$ & $\mathbf{1 0 0 , 0}$
\end{tabular}

\section{Sumber: Data Primer}

Tabel 5 distribusi berdasarkan kejadian Stunting tehadap balita dimana yang mengalami Stunting yaitu 70 orang
(74,5\%) dan yang tidak Stunting yaitu 24 orang $(25,5 \%)$.

Tabel 5. Distribusi Berdasarkan Kejadian Stunting Terhadap Balita di Wilayah Kerja Puskesmas Baraka Kabupaten Enrekang.

\begin{tabular}{ccc}
\hline Stunting & Frekuensi & Persentase \\
\hline Ya & 70 & 74,5 \\
Tidak & 24 & 25,5 \\
\hline Total & $\mathbf{9 4}$ & $\mathbf{1 0 0 , 0}$
\end{tabular}

Sumber: Data Primer

Tabel 6 distribusi berdasarkan ASI eksklusif dengan kejadian Stunting yaitu 31 orang $(33,0 \%)$ balita yang ASI eksklusif sedangkan yang tidak ASI eksklusif terdapat 63 orang $(67,0 \%)$.

Tabel 6. Distribusi Berdasarkan ASI Eksklusif Terhadap Kejadian Stunting Pada Balita di Wilayah Kerja Puskesmas Baraka Kabupaten Enrekang.

\begin{tabular}{ccc}
\hline ASI Eksklusif & Frekuensi & Persentase \\
\hline Ya & 31 & 33,0 \\
Tidak & 63 & 67,0 \\
\hline Total & $\mathbf{9 4}$ & $\mathbf{1 0 0 , 0}$
\end{tabular}

Sumber: Data Primer 
Tabel 7 distribusi berdasarkan MP ASI dengan kejadian Stunting yaitu balita yang MP ASI terdapat 31 orang
(33,0\%) dan yang tidak MP ASI terdapat 63 orang $(67,0 \%)$.

Tabel 7. Distribusi Berdasarkan MP ASI Terhadap Kejadian Stunting Pada Balita di Wilayah Kerja Puskesmas Baraka Kabupaten Enrekang.

\begin{tabular}{ccc}
\hline MP ASI & Frekuensi & Persentase \\
\hline Ya & 31 & 33,0 \\
Tidak & 63 & 67,0 \\
\hline Total & $\mathbf{9 4}$ & $\mathbf{1 0 0 , 0}$
\end{tabular}

\section{Sumber: Data Primer}

Tabel 8 distribusi berdasarkan BBLR dengan kejadianStunting yaitu balita yang BBLR terdapat 9 orang
$(9,6 \%)$ dan yang tidak BBLR terdapat 85 orang $(90,4 \%)$.

Tabel 8. Distribusi Berdasarkan BBLR Terhadap Kejadian Stunting Pada Balita di Wilayah Kerja Puskesmas Baraka Kabupaten Enrekang.

\begin{tabular}{ccc}
\hline BBLR & Frekuensi & Persentase \\
\hline Ya & 9 & 9,6 \\
Tidak & 85 & 90,4 \\
\hline Total & $\mathbf{9 4}$ & $\mathbf{1 0 0 , 0}$
\end{tabular}

\section{Sumber: Data Primer}

Tabel 9 distribusi berdasarkan usia kehamilan dengan kejadian Stunting yaitu balita yang prematur terdapat 23 orang $(24,5 \%)$ dan yang tidak prematur terdapat 71 orang $(75,5 \%)$.

Tabel 9. Distribusi Berdasarkan Usia Kehamilan Terhadap Kejadian Stunting Pada Balita di Wilayah Kerja Puskesmas Baraka Kabupaten Enrekang.

\begin{tabular}{ccc}
\hline Prematur & Frekuensi & Persentase \\
\hline Ya & 23 & 24,5 \\
Tidak & 71 & 75,5 \\
\hline Total & $\mathbf{9 4}$ & $\mathbf{1 0 0 , 0}$
\end{tabular}


Tabel 10 distribusi berdasarkan status gizi ibu (KEK) dengan kejadian Stunting yaitu terdapat 33 orang $(35,1 \%)$ dan yang tidak KEK terdapat 61 orang $(64,9 \%)$.

Tabel 10. Distribusi Berdasarkan Status gizi (KEK Ibu balita) Terhadap Kejadian Stunting Pada Balita di Wilayah Kerja Puskesmas Baraka Kabupaten Enrekang.

\begin{tabular}{ccc}
\hline KEK & Frekuensi & Persentase \\
\hline Ya & 33 & 35,1 \\
Tidak & 61 & 64,9 \\
\hline Total & $\mathbf{9 4}$ & $\mathbf{1 0 0 , 0}$
\end{tabular}

\section{Sumber: Data Sekunder}

Tabel 11 analisis hubungan ASI eksklusif dengan kejadian Stunting pada balita yaitu dari 94 balita terdapat 53 balita Stunting yang tidak mengomsumsi
ASI eksklusif dan 10 orang yang normal, sedangkan balita yang mengomsumsi ASI eksklusif terdapat 17 balita Stunting dan 14 balita normal.

Tabel 11. Hubungan ASI Eksklusif Dengan Kejadian Stunting Pada Balita di Wilayah kerja Puskesmas Baraka Kabupaten Enrekang.

\begin{tabular}{|c|c|c|c|c|c|c|c|}
\hline \multirow{3}{*}{ ASI Eksklusif } & \multicolumn{6}{|c|}{ Kejadian Stunting } & \multirow{3}{*}{$\mathrm{P}$} \\
\hline & \multicolumn{2}{|c|}{ Stunting } & \multicolumn{2}{|c|}{ Normal } & \multicolumn{2}{|c|}{ Jumlah } & \\
\hline & $\mathrm{n}$ & $\%$ & $\mathrm{n}$ & $\%$ & $\mathrm{n}$ & $\%$ & \\
\hline Tidak ASI & 53 & 75,5 & 10 & 41,7 & 63 & 67,0 & \\
\hline Eksklusif & & & & & & & 0,002 \\
\hline ASI Eksklusif & 17 & 24,3 & 14 & 58,3 & 31 & 33,0 & \\
\hline Jumlah & 70 & 74,5 & 24 & 25,5 & 94 & 100 & \\
\hline
\end{tabular}

\section{Sumber: Data Primer}

Tabel 12 analisis hubungan MP ASI dengan kejadian Stunting pada balita yaitu dari 94 balita terdapat 53 balita Stunting yang tidak mengomsumsi MP
ASI dan 10 orang yang normal, sedangkan balita yang mengomsumsi MP ASI terdapat 17 balita Stunting dan 14 balita normal.

Tabel 12. Hubungan MP ASI Dengan Kejadian Stunting Pada Balita di Wilayah Kerja Puskesmas Baraka Kabupaten Enrekang.

\begin{tabular}{cccccccc}
\hline & \multicolumn{5}{c}{ Kejadian stunting } & \multirow{2}{*}{$\mathrm{P}$} \\
\cline { 2 - 6 } MP ASI & \multicolumn{2}{c}{ Stunting } & \multicolumn{2}{c}{ Normal } & \multicolumn{2}{c}{ Jumlah } & \\
\cline { 2 - 6 } & $\mathrm{n}$ & $\%$ & $\mathrm{n}$ & $\%$ & $\mathrm{n}$ & $\%$ & \\
\hline Tidak MP ASI & 53 & 75,5 & 10 & 41,7 & 63 & 67,0 & 0,002 \\
\hline
\end{tabular}




\begin{tabular}{lllllll} 
MP ASI & 17 & 24,3 & 14 & 58,3 & 31 & 33,0 \\
\hline Jumlah & 70 & 74,5 & 24 & 25,5 & 94 & 100
\end{tabular}

\section{Sumber: Data Primer}

Tabel 13 analisis hubungan BBLR dengan kejadian Stunting pada balita yaitu dari 94 balita terdapat 9 balita
Stunting yang mengalami BBLR sedangkan terdapat 61 balita Stunting yang tidak BBLR dan 24 balita normal.

Tabel 13. Hubungan BBLR Dengan Kejadian Stunting di Wilayah kerja Puskesmas Baraka Kabupaten Enrekang.

\begin{tabular}{lccccccc}
\hline \multirow{1}{*}{ BBLR } & \multicolumn{6}{c}{ Kejadian stunting } & \multirow{2}{*}{$\mathrm{P}$} \\
\cline { 2 - 7 } & \multicolumn{2}{c}{ Stunting } & \multicolumn{2}{c}{ Normal } & \multicolumn{2}{c}{ Jumlah } & \\
\cline { 2 - 7 } & $\mathrm{n}$ & $\%$ & $\mathrm{n}$ & $\%$ & $\mathrm{n}$ & $\%$ & \\
\hline BBLR & 9 & 12,9 & 0 & 0,0 & 9 & 9,6 & \multirow{2}{*}{0,106} \\
Tidak BBLR & 61 & 87,1 & 24 & 100 & 85 & 90,4 & \\
\hline Jumlah & 70 & 74,5 & 24 & 25,5 & 94 & 100 &
\end{tabular}

\section{Sumber: Data Primer}

Tabel 14 analisis hubungan usia kehamilan dengan kejadian Stunting pada balita yaitu dari 94 balita terdapat 19 balita Stunting yang prematur dan 4 orang yang normal, sedangkan balita yang tidak prematur terdapat 51 balita Stunting dan 20 normal.

Tabel 14. Hubungan Usia Kehamilan Dengan Kejadian Stunting di Wilayah Kerja Puskesmas Baraka Kabupaten Enrekang.

\begin{tabular}{lccccccc}
\hline \multirow{3}{*}{ Usia Kehamilan } & \multicolumn{6}{c}{ Kejadian stunting } & \multirow{2}{*}{$\mathrm{P}$} \\
\cline { 2 - 6 } & \multicolumn{2}{c}{ Stunting } & \multicolumn{2}{c}{ Normal } & \multicolumn{2}{c}{ Jumlah } & \\
\cline { 2 - 7 } & $\mathrm{n}$ & $\%$ & $\mathrm{n}$ & $\%$ & $\mathrm{n}$ & $\%$ & \\
\hline Prematur & 19 & 21,7 & 4 & 16,7 & 23 & 24,5 & \multirow{2}{*}{0,303} \\
Tidak Prematur & 51 & 72,9 & 20 & 83,3 & 71 & 75,5 & \\
\hline Jumlah & 70 & 74,5 & 24 & 25,5 & 94 & 100 & \\
& & & & & & &
\end{tabular}

\section{Sumber: Data Primer}

Tabel 15 analisis hubungan KEK dengan kejadian Stunting pada balita dari 94 balita terdapat 27 balita Stunting dan
6 orang yang normal, sedangkan yang tidak KEK terdapat 43 balita Stunting dan 18 yang normal. 
Tabel 15. Hubungan KEK (Ibu Balita) Dengan Kejadian Stunting di Wilayah Kerja Puskesmas Baraka Kabupaten Enrekang.

\begin{tabular}{|c|c|c|c|c|c|c|c|}
\hline \multirow{3}{*}{ Status Gizi } & \multicolumn{6}{|c|}{ Kejadian stunting } & \multirow{3}{*}{$P$} \\
\hline & \multicolumn{2}{|c|}{ Stunting } & \multicolumn{2}{|c|}{ Normal } & \multicolumn{2}{|c|}{ Jumlah } & \\
\hline & $\mathrm{n}$ & $\%$ & $\mathrm{n}$ & $\%$ & 11 & $\%$ & \\
\hline KEK & 27 & 38,6 & 6 & 25,0 & 33 & 35,1 & \multirow{2}{*}{0,229} \\
\hline Tidak KEK & 43 & 61,4 & 18 & 75,0 & 61 & 64,9 & \\
\hline Jumlah & 70 & 74,5 & 24 & 25,5 & 94 & 100 & \\
\hline
\end{tabular}

\section{Sumber: Data Sekunder}

\section{PEMBAHASAN}

Jenis penelitian yang digunakan dalam penelitian ini adalah Survey analitik dengan pendekatan Cross Sectional Study yang menjelaskan hubungan variabel-variabel yang ingin diteliti, yang bertujuan untuk menganalisis hubungan variabel bebas, faktor-faktor resiko. Data yang dikumpulkan disusun dalam bentuk tabel distribusi frekuensi disertai dengan penjelasan-penjelasan. Adapun hasil penelitian dari Faktor ASI eksklusif 33,0 balita yang mengomsumsi ASI Eksklusif sedangkan yang tidak mengomsumsi ASI Eksklusif sebanyak 67,0\%. Hal tersebut dipengaruhi oleh faktor dari orang tua yang tidak terlalu memperhatikan dan kurangnya pengetahuan mengenai ASI Eksklusif contohnya memberikan balitanya air putih, madu sebelum memasuki usia 6 bulan. Adapun faktor lain yaitu, pengaruh budaya yang masih kental dengan melakukan pemberian makanan bayi sebelum waktunya seperti memberikan pisang yang dihaluskan dan dicampurkan dengan air diberikan pada bayi yang berusia kurang dari enam bulan.
Hasil penelitian sejalan dengan penelitian yang dilakukan oleh Larasati, Agista (2018) di Puskesmas Pujon Kabupaten Malang yang menyatakan bahwa rendahnya ASI Eksklusif pada kelompok kasus dikarenakan terdapat perilaku-perilaku ibu yang memberikan makanan dan minuman selain ASI sebelum anak berusia enam bulan. Sehingga hasil Chi-square menyatakan bahwa terdapat hubungan yang signifikan antara ASI Eksklusif dengan kejadian Stunting. balita harus menyusu sampai usia dua tahun sesuai dengan rekomendasi WHO. Hal ini dikarenakan ASI telah terbukti memiliki efek positif terhadap daya tahan tubuh balita dan menurunkan resiko kejadian Stunting pada balita

Makanan pendamping ASI (MP ASI) adalah makanan yang diberikan kepada balita pada usia 6 bulan. MP ASI sendiri bersifat untuk melengkapi ASI bukan untuk mengganti ASI dan ASI tetap harus diberikan sampai usia 2 tahun. Dari hasil penelitian menunjukan bahwa dari 94 balita yang diteliti, sebanyak $33,0 \%$ balita yang mengomsumsi MP ASI sedangkan yang tidak mengomsumsi MP ASI sebanyak $67,0 \%$. Hal tersebut dipengaruhi akibat 
pemberian MP ASI terlalu dini yang dilakukan oleh ibu-ibu balita dikarenakan terhentinya pemberian ASI Eksklusif dan persepsi yang muncul dari ibu bahwa ASI tidak cukup dan ASI tidak lancar keluar sehingga anak rewel. Akhirnya ibu memberikan makanan tambahan ke balita sehingga berdampak terhadap balita. Contohnya memberikan balita bubur saring atau pisang sebelum memasuki usia 6 bulan sementara didalam usus bayi belum mampu menyerap makanan tersebut sehingga kesehatan bayi terganggu dan menimbulkan penyakit yang dapat menghambat pertumbuhannya.

Penelitian ini sejalan dengan penelitian sebelumnya yang dilakukan Hairuddin, Abdul (2018) di Kecamatan Simpang kiri Kota Subulussalam Medan dimana pemberiam MP ASI terlalu dini akan menimbulkan resiko terjadinya penyakit. Pemberian MP ASI terlalu awal merupakan fakor terjadinya Stunting dibandingkan dengan anak yang mendapatkan MP ASI sesuai dengan waktunya.Sehingga uji Chi Square menyatakan bahwa terdapat hubungan antara MP ASI dengan kejadian Stunting. Depkes yang menyatakan bahwa gangguan pertumbuhan pada awal masa kehidupan bayi antara lain disebabkan karena kekurangan gizi sejak bayi yaitu pemberian MP ASI terlalu dini. MP ASI tidak cukup gizinya sesuai kebutuhan bayi atau kurang baiknya pola pemberian menurut usia, dan perawatan bayi yang kurang memadai.

BBLR merupakan berat bayi yang lahir kurang dari 2500 gram. Bayi berat lahir rendah yang diiringi dengan komsumsi makanan yang tidak bergizi, pelayanan kesehatan yang tidak layak, dan sering terjadi infeksi pada anak masa pertumbuhan menyebabkan terhambatnya pertumbuhan dan menghasilkan anak yang Stunting. Berdasarkan hasil penelitian menunjukkan bahwa dari yang diteliti, sebanyak 94 balita yang mengalami BBLR dan seluruhnya mengalami Stunting sebanyak 9 balita (100\%). Sedangkan balita yang tidak BBLR sebanyak 85 balita $(90,4 \%)$ di antaranya 61 balita $(87,1 \%)$ yang mengalami Stunting dan 24 balita tidak mengalami Stunting.

Dalam penelitian ini terdapat balita BBLR yang mengalami Stunting yaitu sebanyak 9 balita hal tersebut dikarenakan dampak lanjutan dari BBLR dapat berupa gagal tumbuh (grouth faltering). Seseorang balita yang lahir BBLR akan sulit dalam mengejar ketertinggalan pertumbuhan awal. Pertumbuhan yang tertinggal akan menyebabkan balita tersebut menjadi Stunting. Namun dalam penelitian ini juga terdapat balita Stunting yang tidak BBLR hal tersebut diakibatkan kurangnya asupan gizi yang diberikan sehingga memperlambat pertumbuhan balita.

Penelitian ini sejalan dengan penelitian Irviani ibrahim (2019) yang dilakukan di Wilayah Pegunungan Desa Bontongan Kecamatan Baraka Kabupaten Enrekang yang menyatakan bahwa tidak ada hubungan signifikan antara berat lahir dengan Stunting .Tidak adanya hubungan dikarenakan faktor yang mempengaruhi balita BBLR yaitu 
asupan yang dikomsumsi sehingga untuk mencapai pertumbuhan dan status gizi baik. Pada usia 6 bulan pertama balita dapat mengejar tumbuh kembangnya maka kemungkinan anak dapat tumbuh dengan tinggi badan yang normal, setelah 6 bulan pertumbuhan balita dapat dipengaruhi dengan pemberian ASI Eksklusif dan MP ASI yang tidak intensif dapat memicu pertumbuhan balita menjadi lambat. Hal ini terjadi karena efek berat badan lahir dengan Stunting berada pada usia 6 bulan pertama,kemudian menurun hingga usia 2 tahun.

Usia kehamilan merupakan usia janin dalam kandungan dimana dapat melahirkan balita yang Prematur dan tidak Prematur. Berdasarkan hasil penelitian menunjukkan bahwa semua balita yang di teliti sebanyak 94 orang diantaranya yang lahir Prematur terdapat 19 orang mengalami Stunting, sedangkan lahir normal atau lahir tidak Prematur yang mengalami Stunting terdapat 51 orang. Dalam penelitian ini balita yang banyak terkena Stunting adalah balita yang lahir normal atau tidak Prematur. Hasil penelitian ini menyimpulkan bahwa tidak ada hubungan yang signifikan antara kejadian Stunting dengan usia kehamilan. Dimana usia kehamilan tidak jauh dengan BBLR, tetapi tidak semua balita yang BBLR lahir Prematur. Bayi yang prematur harus diberi penanganan khusus dengan cara dimasukkan ke dalam inkubator.

Hasil penelitian ini berbeda dengan penelitian Pamungkas, Catur Esty (2017) di Kabupaten Lombok Utara mengatakan bahwa ada hubungan yang signifikan antara usia kehamilan dengan kejadian Stunting yang didapatkan bahwa kelahiran prematur telah terbukti meningkatkan morbiditas bagi anak yang bertahan hidup, yaitu gagal tumbuh (Stunting) dalam dua tahun pertama, dapat menempatkan anak pada peningkatan risiko yang akan datang yaitu kejadian morbiditas serius pada akhir masa kanak-kanak dan pengembangan penyakit kronis pada kehidupan dewasa. Namun dalam penelitian ini tidak sejalan dengan penelitian sebelumnya mungkin karena ada faktor lain yang dapat mengakibatkan balita Stunting, misalnya faktor lingkungan dan status gizi yang tidak terpenuhi pada 1000 hari kehidupan balita.

Penelitian Sumardillah, D.S, \& Rahmadi,A. (2019) di Kelurahan Sukaraja Kota Bandar Lampung mengatakan bahwa balita yang lahir cukup bulan apabila asupan gizinya kurang juga akan mengalami growh faltering. Hal ini akan bertambah berat jika ditambah dengan paparan penyakit infeksi, Sebaliknya jika balita prematur yang mengalami growth faltering jika diberikan dukungan asupan gizi yang baik maka pola pertumbuhan normal dapat terkejar.

KEK merupakan kekurangan gizi yang berlangsung kronis hingga menimbulkan gangguan kesehatan pada ibu secara relatif atau absolut satu atau lebih zat gizi. Beberapa hal yang dapat menyebabkan tubuh kekurangan zat gizi seperti jumlah zat gizi yang dikomsumsi kurang. Ibu hamil yang KEK ditandai dengan lingkar lengan atas pada tangan 
yang tidak digunakan dengan kegiatan sehari-hari dengan panjang lingkar $<23,5$ $\mathrm{cm}$. Lingkar lengan atas dapat memberikan gambaran tentang keadaan jaringan otot dan lapisan lemak di bawah kulit. Pendeteksian LILA dilakukan pada saat kunjungan pertama (K1) pemeriksaan Antenatal Care (ANC). Tujuan pengukuran LILA adalah untuk menapis apakah ibu hamil tersebut masuk dalam kategori KEK atau tidak KEK. Tindakan ini penting dilakukan, karena bukan hanya untuk menapis ibu hamil yang KEK tapi juga untuk mengetahui kemungkinan risiko melahirkan Stunting (Nilfar, 2018).

Berdasarkan hasil penelitian menunjukkan bahwa dari 94 balita terdapat 27 Stunting yang ibunya mengalami KEK sedangkan yang tidak KEK terdapat 43 balitanya mengalami Stunting. Hal ini dipengaruhi oleh beberapa faktor yang dapat mempengaruhi status gizi balita yaitu kondisi sosial ekonomi dan asupan gizi yang kurang yang diberikan kepada balita sehingga dapat memperlambat pertumbuhan balita sehingga terjadi Stunting. Sehingga dalam penelitian ini tidak menjamin bahwa ibu yang KEK dapat melahirkan balita Stunting.

Penelitian ini sejalan dengan penelitian Zaif,Mustika R, Wijaya,M \& Hilmanto,D. (2017) di Kecamatan Soreang Kabupaten Bandung yang menyatakan tidak ada hubungan antara KEK dengan kejadian Stunting hal tersebut di pengaruhi oleh beberapa faktor seperti faktor kondisi ekonomi keluarga. Kemiskinan berkaitan erat dengan pertumbuhan anak balita, sehingga peningkatan gizi termasuk pertumbuhan balita harus diiringi dengan upaya peningkatan ekonomi

\section{KESIMPULAN}

Berdasarkan hasil analisis dan pembahasan yang telah diuraikan pada bab sebelumnya, maka kesimpulan yang dapat dihasilkan dari penelitian ini sebagai berikut:

1. Ada hubungan antara ASI Eksklusif dengan kejadian Stunting di wilayah kerja Puskesmas Baraka Kabupaten Enrekang.

2. Ada hubungan antara MP ASI dengan kejadian Stunting di wilayah kerja Puskesmas Baraka Kabupaten Enrekang.

3. Tidak ada hubungan antara BBLR dengan kejadian Stunting di wilayah kerja Puskesmas Kabupaten Enrekang.

4. Tidak ada hubungan antara Usia Kehamilan dengan kejadian Stunting di wilayah Kerja Puskesmas Baraka Kabupaten Enrekang.

5. Tidak ada hubungan antara Status gizi ibu (KEK) dengan kejadian Stunting di wilayah kerja Puskesmas Baraka Kabupaten Enrekang.

\section{UCAPAN TERIMAKASIH}

Dengan selesainya penelitian ini, saya mengucapkan terima kasih kepada seluruh pihak yang banyak memberikan bantuan dalam penyelesaian penelitian ini, terkhusus dosen pembimbing dan lokasi tempat penelitian saya. 


\section{DAFTAR PUSTAKA}

A.Irviani, E, Bujawati., S, Syahrir, \& A.S, Adha, .(2019). Analisis Determinan Kejadian Growth Failure (Stunting) pada Anak Balita Usia 1236 Bulan di Wilayah Pegunungan Desa Bontongan Kecamatan Baraka Kabupaten Enrekang. Al-Sihah: Public Health Science Journal, 11, 50-64.

Dinas Kesehatan Kabupaten Enrekang. (2019). Data Sunting Kabupaten Enrekang Tahun 2019

Hairuddin, Abdul. (2018). Penyakit Infeksi dan Praktek Pemberian MP ASI terhadap Kejadian Stunting pada Anak Usia 12-36 Bulan di Kecamatan Simpang Kiri Kota Subulussalam. Jurnal Dunia Gizi. 1(1), 52-58.

Kementrian Kesehatan RI (2018). Situasi Balita Pendek (Stunting) di Indonesia. Buletin Jendela Data dan Informasi Kesehatan.

http://pusdatin.kemkes.go.id

Larasati, Agista. (2018). Hubungan antara Kehamilan Remaja dan Riwayat Pemberian ASI Dengan Kejadian Stunting pada Balita di Wilayah Kerja Puskesmas Pujon Kabupaten Malang. Amerta Nutrition. Vol 2, No 4 (2018). Doi: org/10.20473/amnt.v2i4.2018.392401

Pamungkas, Esty Catur. (2017). Hubungan Kehamilan Tidak Diinginkan (KTD) Dengan Kejadian Stunting Pada Anak Balita Usia 12-59
Bulan di Wilayah Kerja Puskesmas Gangga Kabupaten Lombok Utara. http://digilib.unisayogya.ac.id/2384/1 INASKAH\%20

PUBLIKASI_CATUR\%20ESTY\%2 OPAMUNGKAS.pdf

Ruaida,Nilfar\&Soumokil,O. (2018). Hubungan Status KEK ibu hamil dan BBLR dengan kejadian Stunting pada balita di Puskesmas Tawiri Kota Ambon. Jurnal Poltekkes Maluku. 9(2), 45-51. www.jurnalpoltekkesmaluku.com

Sumardillah,D.S, \& Rahmadi,A. (2019). Risiko Stunting Anak Baduta ( 7-24 bulan ). Jurnal Kesehatan, 10(April), 93-104.

Yusdarif, et all. (2018). Determinan Kejadian Stunting pada Balita Usia 24-59 bulan di Kelurahan Rangas Kecamatan Banggae Kabupaten Majene. Al Sihah The Public Health Science Journal. Vol 10 No 2

Zaif,Mustika R, Wijaya,M \& Hilmanto,D. (2017). Hubungan antara Riwayat Status Gizi Ibu Masa Kehamilan dengan Pertumbuhan Anak Balita di Kecamatan Soreang Kabupaten Bandung. Jurnal Sistem Kesehatan. Vol 2 No 3. 156-163. 